\title{
A Systematic Approach to Supporting Faculty Knowledge Development in Nursing and Health Informatics
}

\author{
Paula PROCTER ${ }^{\mathrm{a}, 1}$ \\ ${ }^{a}$ Department of Nursing and Midwifery, Sheffield Hallam University, United Kingdom
}

\begin{abstract}
Using a systematic communication strategy the knowledge of nursing/health informatics amongst Faculty members has been developed resulting in the inclusion of informatics across the curriculum as part of the essential role of nurses and other healthcare practitioners in all areas of practice.
\end{abstract}

Keywords. Knowledge acquisition, healthcare informatics, University educators

\section{Introduction}

It has long been recognized that there is a paucity of nurse educators who have the knowledge and skills to include informatics within their curriculum sessions [1], the nurse educators within the Department of Nursing and Midwifery were no exception, although highly competent in their own subject areas. Using a systematic communication strategy all faculty members within a Department of Nursing and Midwifery have received regular information about their personal student's progress within the online module along with the aims and objectives of the section the students are studying. This poster will give details of the communication strategy and the improvement in informatics inclusion in sessions for students.

\section{Methods}

The Department of Nursing and Midwifery at Sheffield Hallam University is one of the largest in England with some 500 undergraduate nurses and midwives entering each academic year; the Department of Allied Health Professionals holds courses for 14 health professions from Operating Department Practitioners and Paramedics to Radiographers and Physiotherapists accounting for a further 500 students per academic year. To provide effective education to the students are over 100 educators. Embedded within the undergraduate curriculum is a three year health informatics online module for nurses, midwives, and allied health professionals, around 2,500 students with 24/7 access per year [2] which has been available to students since 2009, it is maintained by one educator from a nursing background.

\footnotetext{
${ }^{1}$ Corresponding Author, Paula Procter, Professor of Nursing Informatics, Department of Nursing and Midwifery, Sheffield Hallam University, United Kingdom; E-mail: p.procter@shu.ac.uk.
} 
Every student has an Academic Advisor for the period of their undergraduate course. The Academic Advisor usually has 15 students per group and often has responsibility for two groups generally in different years of their studies. Regular tutorial meetings are timetabled to allow for professional updates as well as post clinical placement individual meetings to review clinical competencies as set by the Nursing and Midwifery Council [3] or the Health Care Professions Council [4].

As part of the online provision a communication strategy has been employed to advise the faculty of the current informatics content studied by their students and the rate of progress of each of their students. A week before scheduled meetings between the students and their Academic Advisor data is extracted from the online managed learning system giving the student last access and completion of the learning sections relevant to their stage of their health professional course; the data along with the aims, objectives and overview for the current section (of six) are sent to the Academic Advisor. Through the circulation of the data and information the Academic Advisors - who are the educators across all curricula - are able to develop their knowledge and understanding of up to date key informatics content and issues ranging from national policy and implementation through coding and classification standards to a view of the future including robotics, nano technologies, artificial intelligence and genomics as they will affect healthcare practice.

\section{Results}

In September 2019 a new curriculum was introduced which followed the health policy of integrated care [5] and as such the students from all health professions learn together, informatics is present across the curriculum sessions taught by a variety of nonspecialised educators.

\section{Conclusions}

Using this 'soft' approach has taken time but has enabled a change in attitude and approach of faculty members towards the inclusion of informatics in the curriculum.

\section{Acknowledgements}

The author acknowledges all our nurse, midwife and allied health professional faculty members for their continuing support of informatics in the undergraduate and post graduate curricula.

\section{References}

[1] Kinnunen U-M, Rajalahti E, Cummings E, Borycki EM. Curricula challenges and informatics competencies for nurse educators. Studies in health technology and informatics 232 (2017): 41-48.

[2] Procter PM. Ubiquitous adoption of innovative and supportive information and communications technology across health and social care needs education for clinicians. In Informatics for Health: 
Connected Citizen-Led Wellness and Population Health, EDS Randell, R., Cornet, R., McCowan, Colin., Peek, Niels and Scott, Phillip J. (2017) IOS Press. ISBN 978-1-61499-753-5 (online) pages 358-362.

[3] Nursing and Midwifery Council. Standards for education practice (2018). Available at: https://www.nmc.org.uk/education/standards-for-education2/

[4] Health Care Professions Council. Standards for education practice (2017). Available at: https://www.hcpc-uk.org/resources/standards/standards-of-education-and-training/

[5] National Health Service England. Integrated care (2016). Available at: https://www.england.nhs.uk/integratedcare/ 